\title{
ERECTILE DYSFUNCTION, TESTOSTERONE LEVELS AND DISEASE ACTIVITY IN ANKYLOSING SPONDYLITIS PATIENTS
}

Laís Zanlorenzi ${ }^{1}{ }^{\star}$, Kamilla de Bessa Jorge', Anauá Fernanda S. Cavalcante', Juliana Simioni', Ana Paula Beckhauser ${ }^{1}$, Thelma Larocca Skare', Luciano Heil Junior', Bernardo Sobreiro', Felipe Guzzo Fagundes', Renato Nisihara'

1.Hospital Universitário Evangélico Mackenzie, Curitiba (PR), Brazil.

*Corresponding author: laisznl@gmail.com

\section{BACKGROUND}

Ankylosing spondylitis (AS) is a rheumatic disease with male preference. It has been shown that male patients with AS may have poor sexual performance, but few studies have been done to analyze sexual hormonal levels in this setting. Hence, we studied sexual performance in male patients with AS trying to correlate it with sexual hormonal profile and disease activity.

\section{METHODS}

We included 34 AS patients and 104 controls. Patients and controls answered the International Index of Erectile Dysfunction (IIEF) and had dosing of total testosterone (TT), free testosterone (FT), bioavailable testosterone (BT), SHBG (serum hormone binding globulin), albumin and LH (luteinizing hormone). Ankylosing spondylitis patients had epidemiological, clinical and treatment data obtained from the charts. Ankylosing spondylitis disease activity was measured simultaneously with blood collection through Bath Ankylosing Spondylitis Disease Activity Index (BASDAI), Ankylosing Spondylitis Disease Activity Score (ASDAS-ESR, using erythrocyte sedimentation rate) and ASDAS-CRP (using C reactive protein).

\section{RESULTS}

The IIEF results were worse in AS patients than controls $(p=0.02)$. Total testosterone and SHBG were higher in AS than controls with $p=0.01$ and $p<0.0001$, respectively. Between the two groups, no differences in LH, FT, BT levels (all with $p=n s$ ) were found. In AS patients, the IIEF results did not correlate with TT, SHBG, LH, FT and BT, but a negative association was found with BASDAI $(p=0.001)$ and ASDAS - CRP $(p=0.02)$.

\section{CONCLUSION}

Ankylosing spondylitis patients had worst sexual performance than controls that were linked to disease activity but not to male sexual hormonal profile. 